\title{
Blockchain Technology for Tracing Drug with a Multichain Platform: Simulation Method
}

\author{
Erick Fernando ${ }^{1, *}$, Meyliana $^{1}$, Harco Leslie Hendric Spits Warnars ${ }^{2}$, Edi Abdurachman ${ }^{2}$ \\ ${ }^{1}$ Information Systems Department, School of Information System, Bina Nusantara University, Jakarta, Indonesia 11480
}

${ }^{2}$ BINUS Graduate Program - Doctor of Computer Science, Bina Nusantara University, Jakarta, Indonesia 11480

\begin{tabular}{l} 
A R T I C L E I N F O \\
\hline Article history: \\
Received: 25 August, 2020 \\
Accepted: 24 January, 2021 \\
Online: 05 February, 2021 \\
\hline Keywords: \\
Blockchain technology \\
Multichain \\
Simulation method \\
Tracing Drug \\
\end{tabular}

A B S T R A C T
This study builds the implementation of the traceability process by conducting simulation
tests using business process simulations with the implementation of blockchain technology
to track drugs. This research focus involved stakeholders, including the pharmaceutical
industry, pharmaceutical wholesalers (distributors/wholesalers), health services (drug
stores, hospitals), consumers. Simulation methods are used to describe the distribution and
traceability of drugs. Finally, the research contribution in incorporating blockchain
technology to supply chain management could potentially help in drug traceability. This
study provides an overview of blockchain technology capabilities to find out which
stakeholders and assets are transacted on the blockchain system. A decentralized
Autonomous Organization is an approach to organizing data on the blockchain that defines
all stakeholders identities associated with different addresses. This process can organize
each address's transactions on a special blockchain platform in this study using multichain.
Furthermore, transactions that have occurred cannot be updated or deleted. This simulation
also illustrates some of the blockchain characteristics that must exist, among others,
transparent, distributed, immutable, and peer to peer transactions. This contribution gives
supply chain management, in particular on drug distribution, stronger control over
distribution.

\section{Introduction}

Supply chain management (SCM) is a system management process that occurs to stakeholders (in general: suppliers, wholesalers, retailers, consumers) starting from the process of receiving raw materials from raw material suppliers to manufacturers, to distributing from distributors, retailers to consumers [1-4]. In SCM, distribution is the most important part to bridge every stakeholder in the SCM system. The distribution process supports the company's profitability process because it has a real impact on the related stakeholders' costs and experiences [5]. This distribution occurs throughout the industry, especially in the pharmaceutical industry $[6,7]$. The distribution process occurs in the pharmaceutical industry distributing drugs from the pharmaceutical industry to wholesalers, wholesalers to hospitals or pharmacies, from pharmacies to end consumers (patients or communities) [8]. This distribution process has several problems that occur in the distribution of drugs, including a lot of data that must be identified, namely drug data,

${ }^{*}$ Corresponding Author: Erick Fernando, erick.fernando001@binus.ac.id stakeholders (industry, pharmaceutical wholesalers, health services (drug stores, hospitals), consumers). Data must be integrated to ensure the distribution process is good and correct, and the most important thing is drug data tracing/tracking. The drug distribution process requires a trace process to make it easy to find out that drugs sold in the market are free from suspected counterfeit drugs. The problems that occur in distribution can be solved with blockchain technology. This technology has a more secure platform, which supports auditable storage, data exchange, data integration, data that is easy to trace, distributed data, validated data $[9,10]$.

Many other kinds of research have developed this blockchain technology. One of its features is the ability to trace and trace data on circulating drugs and is believed to minimize counterfeit drugs [11-16]. In its development, the existing literature is an enormous challenge to prove the implementation of blockchain technology for drug tracking/tracing in the market. Apart from the literature, this study also conducted a forum discussion group (FGD) of the pharmaceutical industry, pharmaceutical wholesalers 
(distributors/wholesalers). The results of the FGD, one of the most important processes of drug distribution and following the drug distribution model in general, experienced the problem of suspected counterfeit drugs circulating in the market, which was difficult to trace. Another thing from the FGD is that the Food and Drug Supervisory Agency will register the identity of a drug circulating in the market but (In Indonesian country is BPOM), which is a representative of government institutions as a supervisory body. These data are used as the basis for the available drug data and become part of the simulation test.

This study builds the implementation of the traceability process by conducting simulation tests using business process simulations with the implementation of blockchain technology to track drugs. This research's focus involved stakeholders, including the pharmaceutical industry, wholesalers (distributors/wholesalers), health services (drug stores, hospitals), consumers. A decentralized Autonomous Organization is an approach to organizing data on the blockchain that defines all stakeholders identities associated with different addresses. This process can organize each address's transactions on a special blockchain platform in this study using multichain. The purpose of the research is to understand the supply chain comprehensively, its advantages, and challenges. Finally, the research contribution in incorporating blockchain technology to SCM could potentially help in drug traceability. This contribution gives SCM, in particular, on drug distribution stronger control over distribution.

\section{Literature review}

\subsection{Pharmaceutical Supply Chain Management}

The 1990s saw the beginning of the supply chain. The supply chain begins with interrelated activities in the product transformation process. Product transformation starts from raw materials into finished goods, which are then distributed to consumers. With the increasingly complex development of the supply chain system, further management is needed to get maximum results. Supply chain management (SCM) is a system management process that occurs to stakeholders (in general: suppliers, wholesalers, retailers, consumers) starting from the process of receiving raw materials from raw material suppliers to manufacturers, to distributing from distributors, retailers to consumers [1-4]. SCM is implemented in many companies and industries in various fields, one of which is in the pharmaceutical industry.

Pharmaceutical Supply Chain Management (PSCM) is growing rapidly and plays an important role in the supply of drugs needed by various stakeholders [17-19]. This role ensures the drug distribution process from industry to consumers. This process occurs in the pharmaceutical supply chain, which consists of raw material suppliers, drug manufacturers, pharmaceutical wholesalers (wholesalers/distribution), health services (pharmacies, hospitals, health centers, and drug stores), and customers [8].

\subsection{Blockchain}

The history of blockchain was originally introduced by [20]. At first, it started with financial transactions or cryptocurrency, namely bitcoin. Blockchain technology development has developed from the first version to the latest 3.0 version [21]. The development of version 3.0 of blockchain technology with smart contracts provides enhanced features of blockchain that can support various enterprise systems such as supply chain management [21] to improve the performance of a system that implements it.

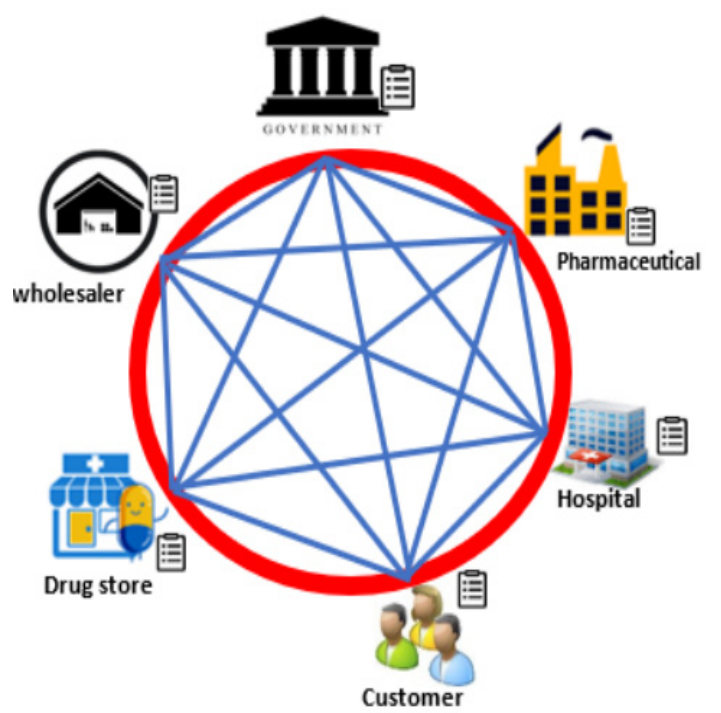

Figure 1: Blockchain Pharmaceutical, Supply Chain Management [5]

\subsection{Multichain Platform}

Multichain is a platform with the application of blockchain technology [22]. Multichain can be applied in all systems in various industries or companies $[22,23]$. Multichain has a structure by having one node in its implementation [24]. In that one node will be able to have several addresses and several assets. The structure of multichain to the user interface can be access by the blockchain in multichain with API.

Blockchain with multichain consists of 3 layers, namely: layer blockchain is Assets, stream, permissions, multi-sig. This layer describes what can use in multichain, Layer Chain, and API. This layer describes the data from layer blockchain how to save or to can read from the next layer is layer UI (multichain explorer). This describes in figure 2.

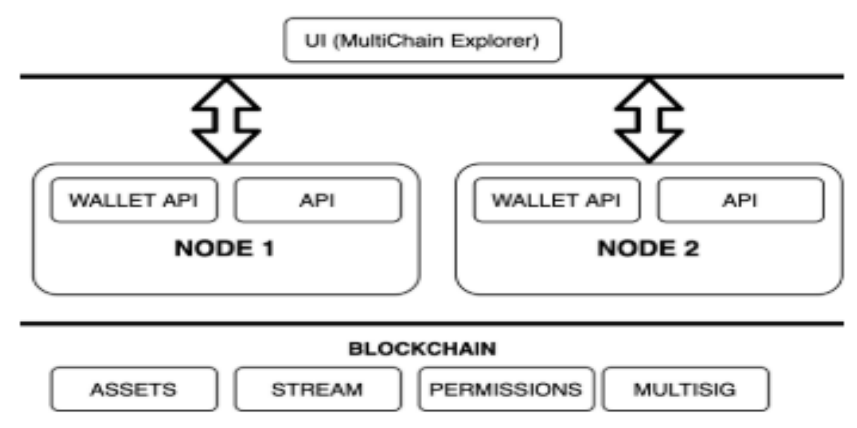

Figure 2: Structure Multichain [22]

\section{Methodology}

In this study, we use the design science research methodology (DSRM) approach. This method is primarily used in information systems [25]. The steps are taken to identify the problem with a focus group discussion (FGD) with the pharmaceutical industry, 
pharmaceutical distributors/wholesalers. Then proceed with developing the model and then carry out the validation process. In this study, validation is carried out to ensure that blockchain technology is able to track drugs circulating in the market in the PSCM system so that the model built can match its purpose. The business model that will be developed will be carried out with a business process simulation (BPS) approach. BPS is a method of business process management to improve business processes and develop new business models. This BPS approach can reduce the costs required and perform system simulations on real business processes. The results can be used for future development considerations [5].

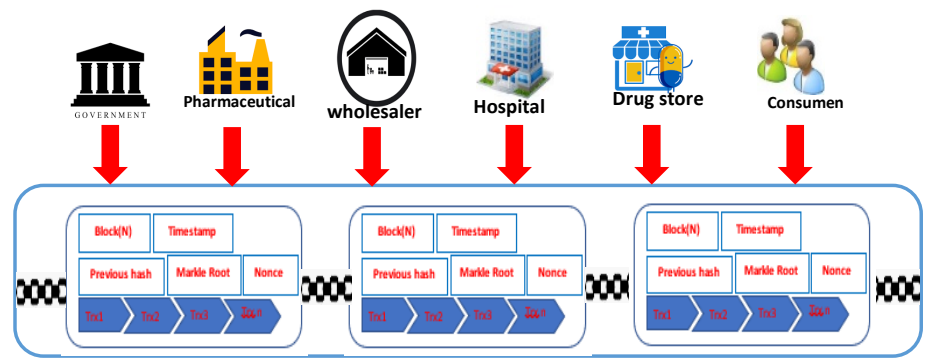

Figure 3: Process Distribution Model with Blockchain [5]

The simulation testing model in this study is based on the business model in Figure 2, which is in accordance with the results of the FGD. The stages start from implementing the script, then the script testing, testing the results, and finally validating the test results. This test is implemented in the blockchain application shown in Figure 4.

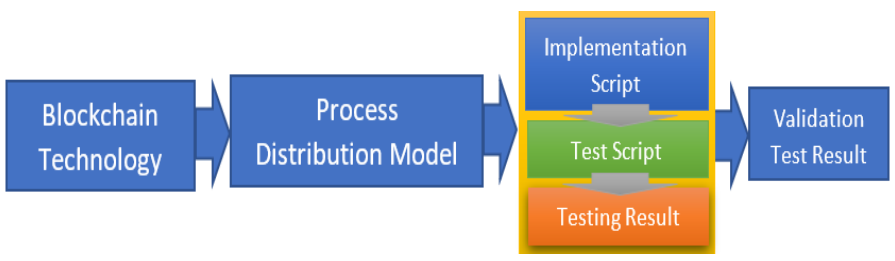

Figure 4: Simulation Process Model

Blockchain technology experiments using the following device environments:

1. Server $\mathrm{O} / \mathrm{S}$

: Ubuntu Server version 18 LTS

2. Blockchain platform : Multichain

3. Node name : Blockchain

4. Version $\quad: 2.0 .2$

5. Protocol $\quad: 10012$

6. Database : : SQLite

7. Node Address $\quad$ : Blockhain@xxx.xxx.163.25:2681

8. Language $\quad:$ JSON, C++, Python

\section{Analysis and discussion}

In this study, a strategy is to map each entity involved in the PSCM business process with an address on the blockchain system and pharmacy drugs as an asset on the blockchain system. Mapping these addresses on the blockchain is the process of creating a Decentralized Autonomous Organization (DAO). DAO is an organization of everything that wants to be related to the blockchain system where the relevant stakeholders, the data that you want to store, use computer code and programs. Thus this organization has the ability to function independently without a centrally regulated authority. DAO designed on a multichain platform can be seen as follows fig 5 and described in table 1.

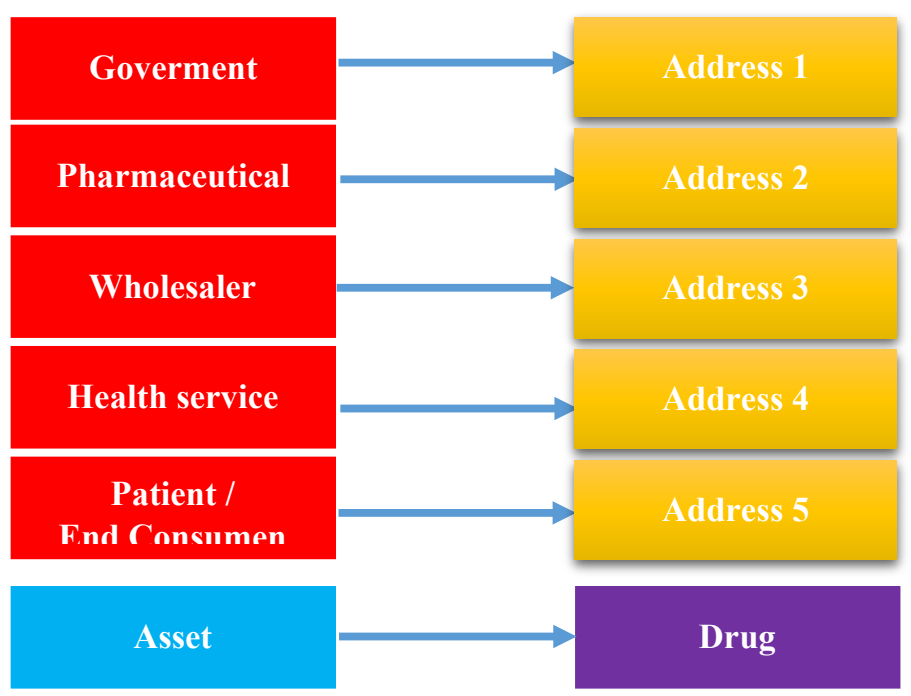

Figure 5: Implementation DAO

Table 1: DAO implementation for different stakeholders

\begin{tabular}{|l|l|}
\hline Stakeholder & Address \\
\hline Government & $\begin{array}{l}\text { 1WUU5Tmzp5Wr9WTB3UFSm8JaPFk } \\
\text { WqmYQ5wSNoH }\end{array}$ \\
\hline Pharmaceutical & $\begin{array}{l}\text { 1N1Jcv3TsUSuYWkADUtNKVeigdrpU } \\
\text { Kititqtab }\end{array}$ \\
\hline Wholesaler & $\begin{array}{l}\text { 1TCZSt6D5vZ3e6vMiaSsMLZ39umwRG } \\
\text { JVbj7U2Z }\end{array}$ \\
\hline $\begin{array}{l}\text { Health service } \\
\text { (drug store) }\end{array}$ & $\begin{array}{l}\text { 177QbpjwmTeFRfkCdHmVkiZQH4Wn } \\
\text { MhYUPRS7jf }\end{array}$ \\
\hline $\begin{array}{l}\text { Patient / End } \\
\text { Consumer }\end{array}$ & $\begin{array}{l}\text { 1GKkwSFs92174KZef37DibNx5b8ee4W } \\
\text { ix1vhZS }\end{array}$ \\
\hline
\end{tabular}

These structures have only one identity stakeholders represented by 32 characters from the hashing result or can be known as a pseudo name on the blockchain.

\subsection{Business processes that are implemented in the simulation}

In the business process testing simulation, starting from the wholesaler/distributor receiving a shipment of 10000 DBL9624502804A1 drug assets (unique drug labels) from the pharmaceutical industry, then the distributor sends 100 DBL9624502804A1 drug assets to drug stores. Then the final consumer buys 10 DBL9624502804A1 drugs as the final process. This test is carried out with a multichain blockchain approach. From the simulation testing process, it can be seen that the process of the blockchain script is mapped one by one in the model for each step, and the simulations carried out can be seen in Table 2 .

Table 2: Implementing Business Process to Blockchain

\begin{tabular}{|l|l|l|}
\hline No & Business Process & Script Blockchain asset \\
\hline 1 & $\begin{array}{l}\text { pharmaceutical } \\
\text { industry registers } \\
\text { drug production } \\
\text { DBL9624502804A1 } \\
\text { of 20000 pack/batch } \\
\text { (this drug code) }\end{array}$ & $\begin{array}{l}\text { Issue 10000 assets named } \\
\text { "DBL9624502804A1" from } \\
\text { (1N1Jcv3TsUSuYGWhaceutical } \\
\text { rpUKititqtab) to Wholesaler }\end{array}$ \\
\hline
\end{tabular}




\begin{tabular}{|l|l|l|}
\hline & & $\begin{array}{l}\text { (1TCZSt6D5vZ3e6vMiaSsMLZ39u } \\
\text { mwRGJVbj7U2Z) }\end{array}$ \\
\hline 2 & $\begin{array}{l}\text { Wholesaler sends } \\
\text { 100 packs of } \\
\text { DBL9624502804A1 } \\
\text { drug production to } \\
\text { drugstores }\end{array}$ & $\begin{array}{l}\text { Issue 100 assets named } \\
\text { "DBL9624502804A1" from } \\
\text { Wholesaler } \\
\text { (1TCZSt6D5vZ3e6vMiaSsMLZ39u } \\
\text { mwRGJVbj7U2Z) to the drug store } \\
\text { (177QbpjwmTeFRfkCdHmVkiZQH4 } \\
\text { WnMhYUPRS7jf) }\end{array}$ \\
\hline 3 & $\begin{array}{l}\text { Drugstores deliver } \\
\text { 100 packs of } \\
\text { DBL9624502804A1 } \\
\text { drug production to } \\
\text { consumers }\end{array}$ & $\begin{array}{l}\text { Issue 10 assets named } \\
\text { "DBL9624502804A1" from the drug } \\
\text { store } \\
\text { (177QbpjwmTeFRfkCdHmVkiZQH4 } \\
\text { WnMhYUPRS7jf) to Konsumen } \\
\text { (1GKkwSFs92174KZef37DibNx5b8 } \\
\text { ee4Wix1vhZS) }\end{array}$ \\
\hline
\end{tabular}

Issue Asset

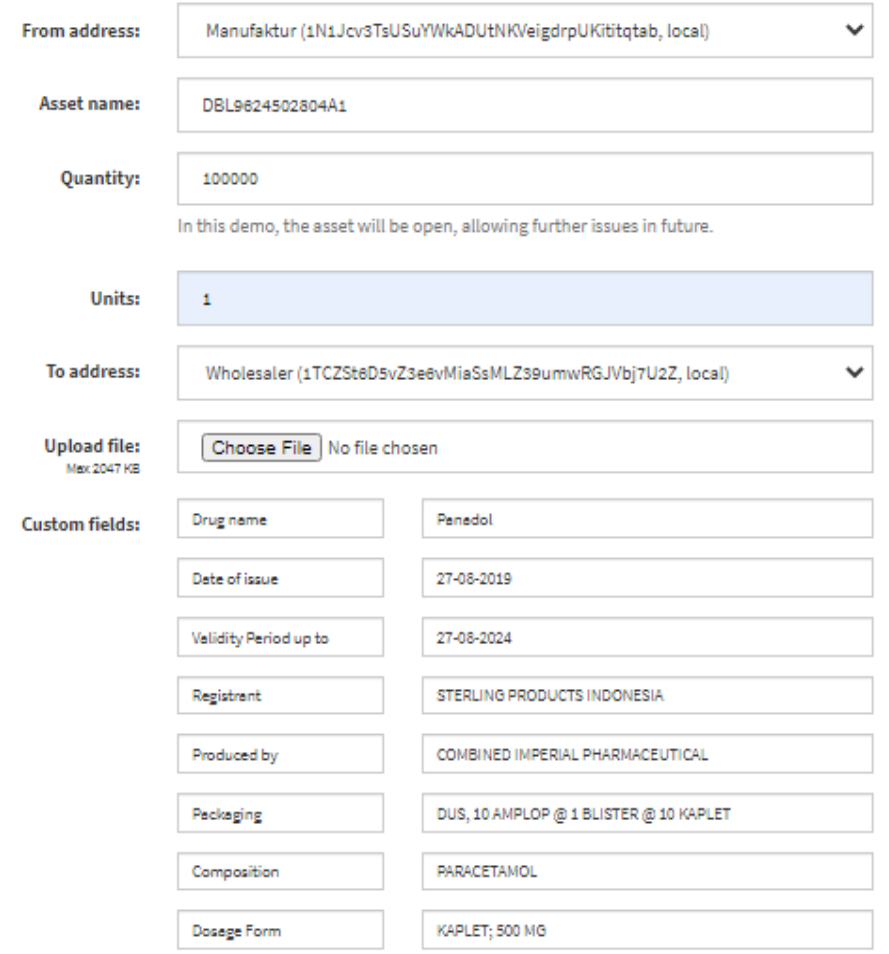

Figure 6: Implementing blockchain with a multichain platform

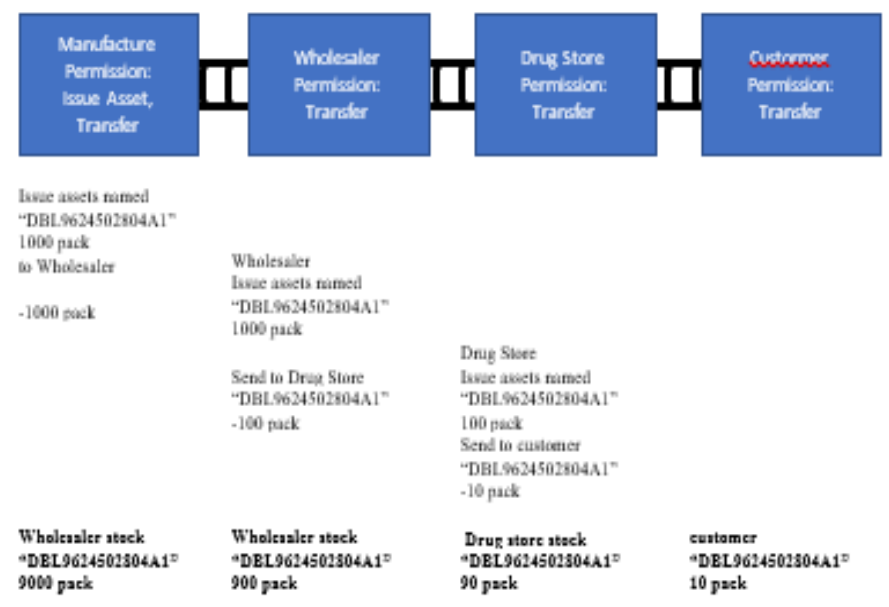

Figure 7: Blockchain transaction described in a block transaction
This business process maps to the blockchain system using a multichain platform where every process that is carried out will have one transaction, which is always recorded in a block. This process simulation shows that this platform can be appropriately used for the recording process of drug distribution.

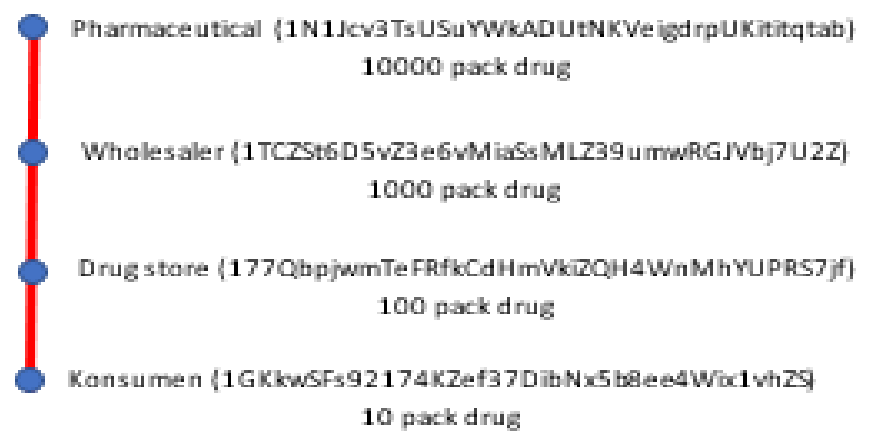

Figure 8: Result tracing drug

\subsection{Benefits of using blockchain in the pharmaceutical industry}

Research an overview of the capabilities of the blockchain so that they can find out which stakeholders and assets are transacted on the blockchain system. Furthermore, transactions that have occurred cannot be updated or deleted. This simulation also illustrates some of the characteristics of the blockchain that must exist, among others, transparent, distributed, immutable, and peer to peer transactions.

This study implements peer to peer transactions that occur in related stakeholders in this system. With the results of technology simulation, testing with business processes serves to track drugs circulating in the market. This tracking also provides information on the final status of existing and circulating drug stocks in the market. The process of validating this simulation test results is carried out according to business processes that have been confirmed to domain experts such as the pharmaceutical industry and wholesalers.

\subsection{Challenges of blockchain technology in the pharmaceutical industry}

The challenge in this simulation process is that every data process that is published on the blockchain is in the form of a unique asset name (drug label name), and this process occurs sequentially to be validated on the blockchain system so it takes time and it is difficult to issue assets. The transaction can be many problem scalabilities.

\section{Conclusion and Future Work}

This study tested a business process simulation of the drug distribution process on the market from related stakeholders. This simulation explains how related stakeholders can interact with the blockchain system using DAO. With this, DAO initializes existing stakeholders with addresses that are formed using code and programming so that these stakeholders have a unique identity on the blockchain system. This study, using a multichain platform for simulation testing. This simulation test illustrates that the application of business processes in drug distribution can be implemented properly. So, that you can see the characteristics of the blockchain, including peer to peer (transactions that occur 
directly with related stakeholders), cute (data cannot be changed because the transaction is hashing), and can be traced well to the drug distribution process.

This study is limited due to the pharmaceutical industry's lack of permission for various information related to the transaction process. The simulation testing system implements blockchain technology as it is by using multichain. The test process with this simulation has excellent results because it can describe the drug distribution business process that runs on blockchain technology using DAO. The next research will improve the blockchain technology infrastructure currently happening directly to multichain admin features. So that in the future, it is hoped that other support modifications can be made, such as a complete dashboard using API as integration with blockchain, implementable off-chain smart contracts, and direct development of business processes that occur in the pharmaceutical industry.

\section{Reference}

[1] J. Wu, M. Ulieru, M. Cobzaru, D. Norrie, "Supply chain management systems: state of the art and vision," in Proceedings of the 2000 IEEE International Conference on Management of Innovation and Technology. ICMIT 2000. "Management in the 21st Century" (Cat. No.00EX457), IEEE: 759-764, 2000, doi:10.1109/ICMIT.2000.916799.

[2] A.P. Barbosa-Póvoa, C. da Silva, A. Carvalho, "Opportunities and challenges in sustainable supply chain: An operations research perspective," European Journal of Operational Research, 268(2), 399-431, 2018, doi:10.1016/j.ejor.2017.10.036.

[3] D.M. Lamberth, C. Cooper, M. Pagh, D. Janus, "Supply Chain Management : Implementation Issues and Research Opportunities," The International Journal of Logistics Management, 9(2), 1998.

[4] R.H. Ballou, "The evolution and future of logistics and supply chain management," Production, 16(3), 375-386, 2006, doi:10.1590/S010365132006000300002

[5] E. Fernando, Meyliana, H.L.H.S. Warnars, E. Abdurachman, "Blockchain technology for pharmaceutical drug distribution in Indonesia: A proposed model," ICIC Express Letters, 14(2), 113-120, 2020, doi:10.24507/icicel.14.02.113.

[6] E. Fernando, M. Meyliana, H.L. Hendric Spits Warnars, E. Abdurachman, "Key strategic issues pharmaceutical industry of SCM: A systematic literature review," Bulletin of Electrical Engineering and Informatics, 9(2), 808-817, 2020, doi:10.11591/eei.v9i2.1264.

[7] E. Fernando, Meyliana, Surjandy, "Blockchain Technology Implementation in Raspberry Pi for Private Network," Proceedings of 2019 4th International Conference on Sustainable Information Engineering and Technology, SIET 2019, 154-158, 2019, doi:10.1109/SIET48054.2019.8986053.

[8] T.K. Mackey, G. Nayyar, "A review of existing and emerging digital technologies to combat the global trade in fake medicines," Expert Opinion on Drug Safety, 16(5), 587-602, 2017, doi:10.1080/14740338.2017.1313227.

[9] R.Y. Garankina, E.R. Zakharochkina, I.F. Samoshchenkova, N.Y. Lebedeva, A. V. Lebedev, "Blockchain technology and its use in the area of circulation of pharmaceuticals," Journal of Pharmaceutical Sciences and Research, 10(11), 2715-2717, 2018.

[10] R. Niblett, Higher education, Nature, 308(5961), 683, 1984, doi:10.1038/308683b0.

[11] K. Fan, Y. Ren, Z. Yan, "Drugledger: A Practical Blockchain System for Drug Traceability and Regulation," 2018 IEEE International Conference on Internet of Things (IThings) and IEEE Green Computing and Communications (GreenCom) and IEEE Cyber, Physical and Social Computing (CPSCom) and IEEE Smart Data (SmartData), 1349-1354, 2018, doi:10.1109/Cybermatics.

[12] A. Jeppsson, O. Olsson, "Blockchains as a solution for traceability and transparency," Lund University Publications Journal, 1-102, 2017.

[13] R.B. Da Silva, C.A. de Mattos, "Critical success factors of a drug traceability system for creating value in a pharmaceutical supply chain (PSC)," International Journal of Environmental Research and Public Health, 16(11), 2019, doi:10.3390/ijerph16111972.

[14] R. Kumar, R. Tripathi, "Traceability of counterfeit medicine supply chain through Blockchain," 2019 11th International Conference on
Communication Systems and Networks, COMSNETS 2019, 2061(1), 568570, 2019, doi:10.1109/COMSNETS.2019.8711418.

[15] M. Pournader, Y. Shi, S. Seuring, S.C.L. Koh, "Blockchain applications in supply chains, transport and logistics: a systematic review of the literature," International Journal of Production Research, 58(7), 2063-2081, 2020, doi:10.1080/00207543.2019.1650976.

[16] M. Benchoufi, R. Porcher, P. Ravaud, "Blockchain protocols in clinical trials: Transparency and traceability of consent," F1000Research, 6, 1-66, 2017, doi:10.12688/f1000research.10531.1.

[17] S.R. Bryatov, A.A. Borodinov, "Blockchain technology in the pharmaceutical supply chain: Researching a business model based on Hyperledger Fabric," CEUR Workshop Proceedings, 2416, 134-140, 2019.

[18] J.D. Evans, "Improving the Transparency of the Pharmaceutical Supply Chain through the Adoption of Quick Response (QR) Code, Internet of Things (IoT), and Blockchain Technology: One Result: Ending the Opioid Crisis," Pittsburgh Journal of Technology Law and Policy, 19(1), 2019, doi:10.5195/tlp.2019.227.

[19] E. Fernando, H. Leslie, H. Spits, E. Abdurachman, "Blockchain Technology Factor for Improve Good Distribution Practice in the Pharmaceutical Industry," International Journal of Recent Technology and Engineering, 8(6), 2174-2180, 2020, doi:10.35940/ijrte.f7181.038620.

[20] S. Nakamoto, "Bitcoin: A Peer-to-Peer Electronic Cash System," Www.Bitcoin.Org, 9, 2008, doi:10.1007/s10838-008-9062-0.

[21] M. Swan, Blockchain for a New Economy, 1st ed., O'Reilly Media, Inc., 1005 Gravenstein Highway North, Sebastopol, CA 95472, USA, 2015.

[22] A. Ismailisufi, T. Popovic, N. Gligoric, S. Radonjic, S. Sandi, "A Private Blockchain Implementation Using Multichain Open Source Platform," 2020 24th International Conference on Information Technology, IT 2020, (February), 24-27, 2020, doi:10.1109/IT48810.2020.9070689.

[23] D. Soto Setzke, M. Böhm, H. Krcmar, The role of openness and extension modularization in value capture for platform-based digital transformation, 2020, doi:10.1007/978-3-030-53337-3 11 .

[24] multichain, Multichain, Www.Multichain.Com, 2020.

[25] K. Peffers, T. Tuunanen, M.A. Rothenberger, S. Chatterjee, "A Design Science Research Methodology for Information Systems Research,” Journal of Management Information Systems, 24(3), 45-77, 2008, doi:10.2753/mis0742-1222240302. 